\title{
Quality and quantity of broad bean seeds protected against Bruchus rufimanus Boh. with non-chemical products
}

\author{
Jakość i ilość nasion bobu chronionego \\ przed strąkowcem bobowym preparatami niechemicznymi
}

\author{
Janina Gospodarek, Elżbieta Boligłowa, Katarzyna Gleń, Milena Rusin
}

\section{Summary}

The investigations were conducted to determine the effect of broad bean protection using non-chemical products (Polyversum WP, Bioczos BR and Biosept $33 \mathrm{SL}$ ) on degree of seed damages caused by Bruchus rufimanus Boh. and energy and capacity of seed germination. The obtained results were compared with the standard method of plant control with artificially synthesised plant protections products (Vitavax 200 FS, Decis 2,5 EC, Fastac 100 EC and Penncozeb 80 WP). Protection method with using non-chemical products did not significantly impact the degree of damage by $B$. rufimanus. Seeds collected from plants protected only with Polyversum WP and Vitavax 200 FS had a higher germination energy than unprotected plants. However, analyzed means of protecting beans did not affect the germination capacity of seeds and most of the morphological features of germinating seedlings.

Key words: Bruchus rufimanus Boh., Bioczos BR, Polyversum WP, germination

\section{Streszczenie}

Celem badań było określenie wpływu stosowania w ochronie bobu odmiany Windsor Biały niechemicznych preparatów (Polyversum WP, Bioczos BR oraz Biosept $33 \mathrm{SL}$ ), na stopień uszkodzenia nasion przez strąkowca bobowego oraz ich energię i zdolność kiełkowania. Uzyskane efekty porównano ze standardową metodą ochrony z wykorzystaniem preparatów chemicznych (Vitavax 200 FS, Decis 2,5 EC, Fastac 100 EC i Penncozeb 80 WP). Zastosowana ochrona z wykorzystaniem preparatów niechemicznych nie wpłynęła istotnie na stopień uszkodzenia nasion przez strąkowca bobowego. Nasiona pochodzące z roślin chronionych wyłącznie zaprawami Polyversum WP oraz Vitavax 200 FS charakteryzowały się wyższą energią kiełkowania niż z roślin niechronionych. Analizowane sposoby ochrony bobu nie wpływały na zdolność kiełkowania nasion oraz nie zmieniały większości cech morfologicznych kiełkujących siewek.

Słowa kluczowe: Bruchus rufimanus Boh., Bioczos BR, Polyversum WP, kiełkowanie

Uniwersytet Rolniczy im. Hugona Kołłątaja w Krakowie

Katedra Ochrony Środowiska Rolniczego

Al. Mickiewicza 21, 31-120 Kraków

rrjgospo@cyf-kr.edu.pl 


\section{Wstęp / Introduction}

Preparaty na bazie wyciagów roślinnych, których przykładami mogą być Bioczos BR, czy też Biosept $33 \mathrm{SL}$ mogą być alternatywą dla ochrony chemicznej z punktu widzenia możliwości wspierania bioróżnorodności zespołu wrogów naturalnych szkodników, a także bezpieczeństwa środowiskowego. Mogą one także stanowić element ochrony integrowanej. Jakość i plon nasion bobu mogą być silnie ograniczane żerowaniem m.in. strąkowca bobowego Bruchus rufimanus Boh. Szkodnik ten obniża zarówno jakość nasion uprawianych na zbiór do bezpośredniego spożycia, jak też energię i zdolność kiełkowania nasion przeznaczanych na materiał siewny. Chociaż w literaturze istnieje bardzo dużo doniesień na temat właściwości insektycydalnych substancji pochodzenia roślinnego (Isman 2000), to tylko nieliczne omawiaja ich wpływ na chrząszcze z rodzaju Bruchus. Wykazano m.in. przydatność olejków z roślin Satureja hortensis L. i Origanum acutidens (Hand.-Mazz.) jako roślinnych bioinsektycydów do zwalczania B. dentipes Baudi (Tozlu i wsp. 2011). Także olejki eteryczne z roślin Artemisia princeps Pamp. i Cinnamomum camphora Ness et Eberm. wykazywały działanie repelentne $\mathrm{i}$ insektycydalne $\mathrm{w}$ odniesieniu do chrząszczy B. rufimanus (Liu i wsp. 2006). Wykazano skuteczność ochrony grochu siewnego (Wenda-Piesik i Piesik 2009) i bobu (Gospodarek i wsp. 2012a) z użyciem preparatu Bioczos BR przed oprzędzikami. Również w odniesieniu do szkodników żerujących na nasionach takich, jak: wołki i trojszyki, olejek z czosnku wykazywał wysoką skuteczność (Huangi wsp. 2000; Feng-Lian i wsp. 2010).

Celem badań było określenie wpływu stosowania w ochronie bobu odmiany Windsor Biały niechemicznych preparatów: Polyversum WP, Bioczos BR oraz Biosept $33 \mathrm{SL}$, na stopień uszkodzenia nasion przez strąkowca bobowego oraz ich energię i zdolność kiełkowania. Uzyskane efekty porównano ze standardową metodą ochrony $\mathrm{z}$ wykorzystaniem preparatów chemicznych: Vitavax 200 FS, Decis 2,5 EC, Fastac 100 EC, Penncozeb 80 WP.

\section{Materiały i metody / Materials and methods}

Doświadczenie przeprowadzono w latach 2011-2012 w Stacji Doświadczalnej - Prusy, należącej do Uniwersytetu Rolniczego w Krakowie. Założono je w trzech powtórzeniach, metodą losowanych bloków. Obserwacje prowadzono na bobie (Vicia faba L.) odmiany Windsor Biały. Doświadczenie obejmowało następujące obiekty: 1. Kontrola - bez ochrony; 2. Obiekt chroniony z użyciem zaprawy Polyversum WP, zastosowanej przed siewem w dawce $10 \mathrm{~g} / \mathrm{kg}$ nasion; 3. Obiekt chroniony z użyciem: zaprawy Polyversum WP, zastosowanej jak w obiekcie 2., preparatu Bioczos BR, stosowanego 4-krotnie w dawce $4 \mathrm{kostki} / \mathrm{l}$ wody (zabiegi opryskiwania wykonywano zależnie od przebiegu warunków atmosferycznych w odstępach 7-12 dniowych, od momentu zauważenia pierwszych kolonii mszycy burakowej Aphis fabae Scop.) oraz preparatu Biosept $33 \mathrm{SL}$, zastosowanego jednorazowo przed kwitnieniem w dawce 2 1/ha; 4. Obiekt chroniony z użyciem zaprawy Vitavax 200 FS, zastosowanej przed siewem $\mathrm{w}$ dawce $4 \mathrm{ml} / \mathrm{kg}$ nasion; 5. Obiekt chroniony z użyciem zaprawy Vitavax 200 FS, zastosowanej jak w obiekcie 4. oraz poprzez opryskiwanie insektycydami Decis 2,5 EC w dawce 0,25 1/ha (2-krotnie) i Fastac $100 \mathrm{EC}$ w dawce 0,09 1/ha (jednorazowo), a także fungicydem Penncozeb $80 \mathrm{WP}$ w dawce $2 \mathrm{~kg} / \mathrm{ha}$ przed kwitnieniem. Insektycydy po raz pierwszy stosowano w momencie pojawienia się mszyc, następnie zabieg opryskiwania powtórzono po 7 dniach, a trzeci zabieg wykonywano $\mathrm{w}$ okresie przekwitania pierwszego piętra kwiatostanów.

Ocenę szkodliwości strąkowca bobowego przeprowadzono w fazie pełnej dojrzałości nasion, na podstawie liczby i masy nasion uszkodzonych w stosunku do ogólnej liczby i masy nasion, analizując nasiona zebrane z 15 losowo wybranych roślin $\mathrm{z}$ poletka. W tym samym czasie oceniono także średni plon nasion z rośliny. Ocenę energii i zdolności kiełkowania nasion bobu przeprowadzono w warunkach laboratoryjnych, zgodnie z ogólnie przyjętymi normami. Wykorzystano nasiona nieuszkodzone przez strąkowca bobowego. Test przeprowadzono w szalkach Petriego. Jako podłoża użyto bibuły. Energię kiełkowania badano po 4 dniach, a zdolność kiełkowania po 14 dniach.

Analizę statystyczną uzyskanych wyników przeprowadzono z wykorzystaniem programu Statistica 10.0 PL. Wykonano analizę wariancji jednoczynnikową, a średnie różnicowano przy pomocy testu NIR Fishera na poziomie istotności $\alpha=0,05$. Dla wybranych parametrów obliczono także błąd standardowy średniej $( \pm$ SE) i odchylenie standardowe $( \pm \mathrm{SD})$.

\section{Wyniki i dyskusja / Results and discussion}

Zarówno liczba strąków, nasion, jak i masa nasion różniły się istotnie pomiędzy analizowanymi latami. Bardziej korzystnym dla bobu okazał się rok 2011. Rośliny wytwarzały średnio o 1,21 strąka więcej, liczba nasion z rośliny była prawie 2-krotnie wyższa, natomiast średnia masa nasion $z$ rośliny ponad 3 -krotnie wyższa (rys. 1). Nie stwierdzono natomiast istotnego zróżnicowania w stopniu uszkodzenia nasion przez strąkowca bobowego - wynosił on około 20-25\%. We wcześniejszych badaniach autorów, na odmianie Hangdown Biały stwierdzono uszkodzenie nasion na poziomie 35-40\% (Gospodarek i wsp. 2012b), zaś w badaniach Wnuka i Wojciechowicz-Żytko (2010) między 36 a $76 \%$.

Zastosowany wariant ochrony z użyciem insektycydów sztucznie syntetyzowanych w roku 2011 wykazał istotny, korzystny wpływ na wzrost bobu, a tym samym na ilość wytworzonych nasion - masa nasion $\mathrm{z}$ rośliny była w tym przypadku prawie 2-krotnie wyższa niż w obiekcie, gdzie bób nie był objęty żadną ochroną (tab. 1). Ochrona z użyciem zaprawy Polyversum WP, jak również z dodatkowymi zabiegami opryskiwania preparatami Bioczos BR i Biosept $33 \mathrm{SL}$, nie wykazała istotnego wpływu na wspomniane cechy. W sezonie 2012 nie odnotowano już tak istotnego oddziaływania ze strony ochrony chemicznej. Opisane wcześniej parametry miały co prawda korzystniejsze wartości w obiekcie chronionym preparatami 

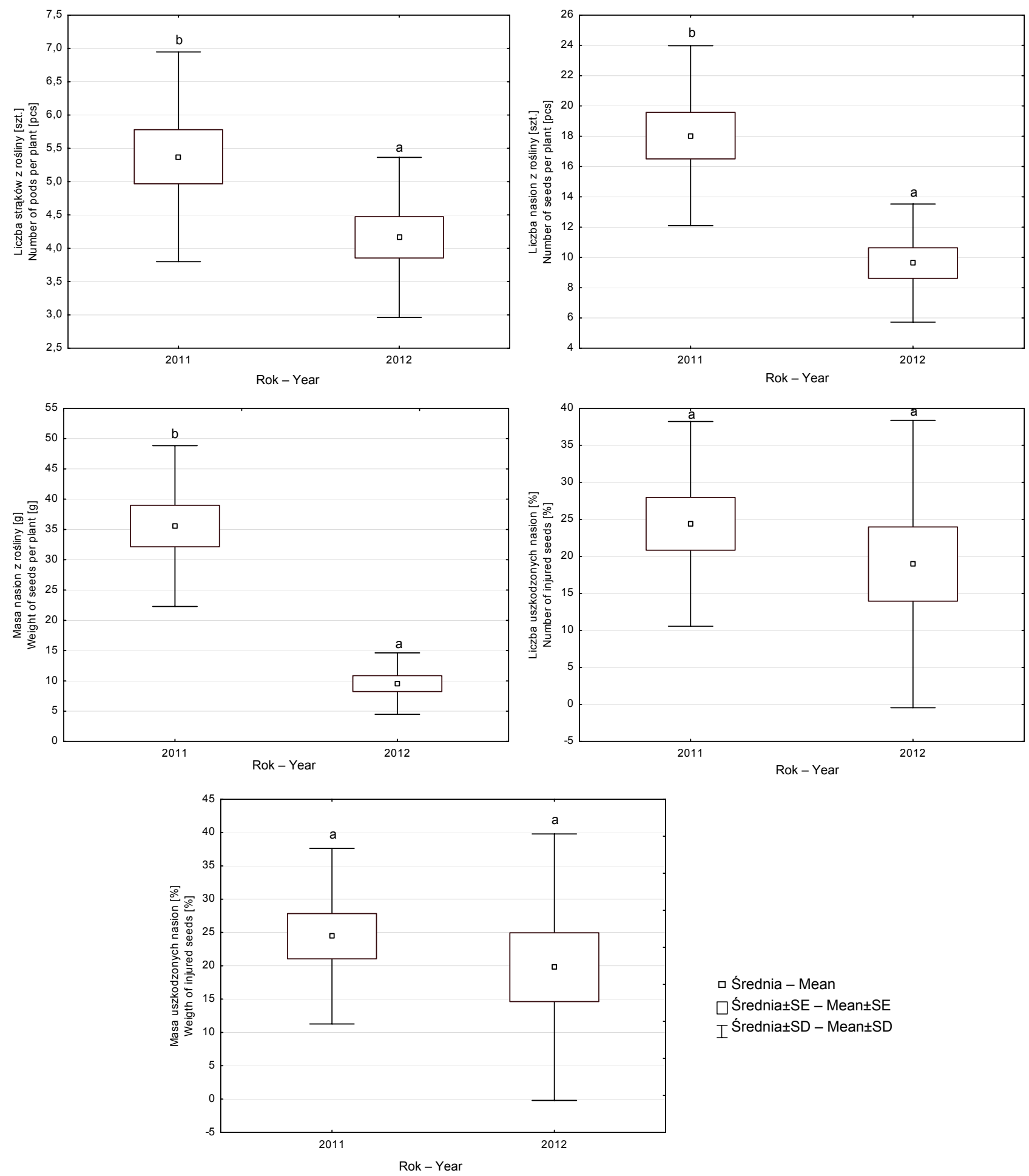

Wartości oznaczone takimi samymi literami odpowiednio dla danej cechy nie różnią się istotnie przy $\alpha=0,05$ Values followed by the same letters for individual features are not significantly different at $\alpha=0.05$

Rys. 1. Średnia liczba strąków i nasion bobu, masa nasion oraz stopień ich uszkodzenia przez strąkowca bobowego

Fig. 1. Average pods and seeds number of broad bean, weight of seeds and degree of injuries caused by broad bean beetle

chemicznymi niż w przypadku obiektu niechronionego, ale obserwowany wpływ nie był udowodniony statystycznie. W tym sezonie stwierdzono natomiast istotne, korzystne oddziaływanie preparatów Bioczos BR i Biosept 33 SL na masę nasion wytworzonych przez rośliny.
W roku 2011 najmniej nasion uszkodzonych przez strąkowca bobowego stwierdzono w obiekcie, gdzie stosowano ochronę $\mathrm{z}$ użyciem insektycydów sztucznie syntetyzowanych. Różnice w odniesieniu do obiektu kontrolnego mieściły się jednak w zakresie błędu 

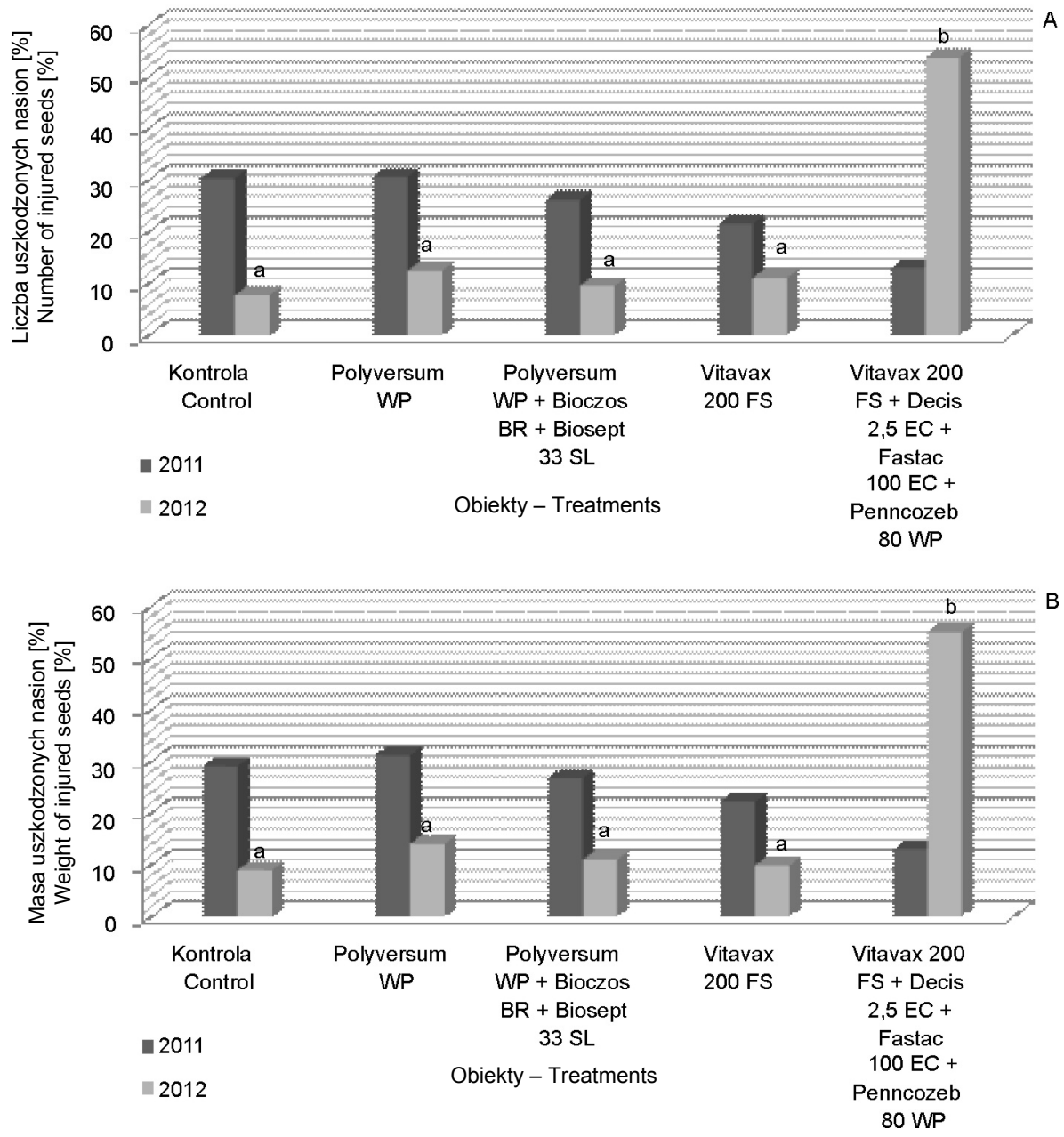

Wartości oznaczone różnymi literami odpowiednio dla danego roku różnia się istotnie przy a =0,05, oznaczenia prezentowano tylko wówczas, gdy istniało zróżnicowanie statystyczne

Values followed by different letters in a given year respectively are statistically different at $\alpha=0.05$, symbols were presented only if there was statistical differentiation

Rys. 2. Odsetek liczby (A) i masy (B) nasion uszkodzonych przez strąkowca bobowego zależnie od zastosowanego sposobu ochrony Fig. 2. Percent of number (A) and weight (B) of seeds injured by B. rufimanus depending on the used protection method

Tabela 1. Średnia liczba strąków i nasion oraz masa nasion z roślin bobu chronionego z użyciem preparatów niechemicznych i chemicznych

Table 1. Average pods and seeds number and weight of seeds collected from broad bean plants protected with non-chemical and chemical products

\begin{tabular}{|c|c|c|c|c|c|c|}
\hline \multirow[t]{2}{*}{$\begin{array}{c}\text { Obiekty } \\
\text { Treatments }\end{array}$} & \multicolumn{2}{|c|}{$\begin{array}{c}\text { Liczba strakków z rośliny } \\
\text { [\% w stosunku do kontroli] } \\
\text { Pods number per plant } \\
\text { [\% relative to control] }\end{array}$} & \multicolumn{2}{|c|}{$\begin{array}{c}\text { Liczba nasion z rośliny } \\
\text { [\% w stosunku do kontroli] } \\
\text { Seeds number per plant } \\
\text { [\% relative to control] }\end{array}$} & \multicolumn{2}{|c|}{$\begin{array}{c}\text { Masa nasion } \mathrm{z} \text { rośliny } \\
\text { [\% w stosunku do kontroli] } \\
\text { Seeds weight per plant } \\
\text { [\% relative to control] }\end{array}$} \\
\hline & 2011 & 2012 & 2011 & 2012 & 2011 & 2012 \\
\hline Kontrola-Control & $100 \mathrm{a}$ & $100 \mathrm{a}$ & $100 \mathrm{a}$ & $100 \mathrm{a}$ & $100 \mathrm{a}$ & $100 \mathrm{ab}$ \\
\hline Polyversum WP & $84,25 \mathrm{a}$ & $119,08 \mathrm{a}$ & $82,35 \mathrm{a}$ & $112,60 \mathrm{a}$ & $90,53 \mathrm{a}$ & $115,34 \mathrm{ab}$ \\
\hline $\begin{array}{l}\text { Polyversum WP } \\
+ \text { Bioczos BR } \\
+ \text { Biosept 33 SL } \\
\end{array}$ & 95,89 a & $162,50 \mathrm{a}$ & 95,74 a & $172,04 \mathrm{a}$ & $101,41 \mathrm{a}$ & $191,56 \mathrm{~b}$ \\
\hline Vitavax $200 \mathrm{FS}$ & $117,81 \mathrm{a}$ & $92,11 \mathrm{a}$ & $112,37 \mathrm{a}$ & $87,22 \mathrm{a}$ & $116,09 \mathrm{a}$ & $80,56 \mathrm{a}$ \\
\hline $\begin{array}{l}\text { Vitavax } 200 \mathrm{FS}+\text { Decis } \\
2,5 \mathrm{EC}+\text { Fastac } 100 \mathrm{EC} \\
+ \text { Penncozeb } 80 \mathrm{WP}\end{array}$ & $154,11 \mathrm{~b}$ & $142,77 \mathrm{a}$ & $158,42 \mathrm{~b}$ & $174,73 \mathrm{a}$ & $194,26 \mathrm{~b}$ & $169,86 \mathrm{ab}$ \\
\hline
\end{tabular}

Wartości oznaczone różnymi literami w kolumnach różnią się istotnie statystycznie $(\alpha=0,05)$

Values marked by different letters in columns are statistically different $(\alpha=0.05)$ 
Tabela 2. Cechy morfologiczne kiełkujących nasion bobu chronionego z użyciem preparatów niechemicznych i chemicznych Table 2. Morphological features of germinating seeds of broad bean protected with non-chemical and chemical products

\begin{tabular}{l|c|c|c}
\hline \multicolumn{1}{c|}{$\begin{array}{c}\text { Obiekty } \\
\text { Treatments }\end{array}$} & $\begin{array}{c}\text { Długość } \\
\text { części nadziemnej } \\
\text { Shoot length } \\
{[\mathrm{cm}]}\end{array}$ & $\begin{array}{c}\text { Długość cześci podziemnej } \\
\text { Underground part length } \\
{[\mathrm{cm}]}\end{array}$ & $\begin{array}{c}\text { Liczba korzeni bocznych } \\
>2 \text { mm długości } \\
\text { Number of lateral roots } \\
>2 \text { mm of length }\end{array}$ \\
\hline Kontrola - Control & $6,79 \mathrm{~b}$ & $8,75 \mathrm{a}$ & $23,03 \mathrm{~b}$ \\
\hline Polyversum WP & $4,37 \mathrm{a}$ & $6,92 \mathrm{a}$ & $16,82 \mathrm{ab}$ \\
\hline $\begin{array}{l}\text { Polyversum WP + Bioczos BR } \\
+ \text { Biosept 33 SL }\end{array}$ & $5,73 \mathrm{~b}$ & $8,90 \mathrm{a}$ & $15,01 \mathrm{a}$ \\
\hline Vitavax 200 FS & $6,25 \mathrm{~b}$ & $8,20 \mathrm{a}$ & $15,28 \mathrm{ab}$ \\
\hline $\begin{array}{l}\text { Vitavax 200 FS + Decis 2,5 EC } \\
+ \text { Fastac 100 EC + Penncozeb 80 WP }\end{array}$ & $6,66 \mathrm{~b}$ & $8,44 \mathrm{a}$ & $16,43 \mathrm{ab}$ \\
\hline
\end{tabular}

Wartości oznaczone różnymi literami w kolumnach różnią się istotnie statystycznie $(\alpha=0,05)$

Values marked by different letters in columns are statistically different $(\alpha=0.05)$

statystycznego (rys. 2). W roku 2012 strąkowiec bobowy wręcz więcej nasion uszkodził w obiekcie chronionym chemicznie, niż w obiekcie nie objętym żadną ochroną. Można to thumaczyć bardzo licznym występowaniem mszycy burakowej w tym właśnie roku, co sprawiło, że w obiekcie pozbawionym ochrony kwiaty zasychały. Strąki i nasiona były przez bób w tym obiekcie wytwarzane później - z kwiatów, które pojawiły się, kiedy mszyce zostały już zniszczone przez czynniki abiotyczne i wrogów naturalnych. W ten sposób nastapiło rozminięcie się w czasie okresu, kiedy strąkowiec bobowy składa jaja w największej liczebności oraz obecności strąków na roślinach niechronionych. Rośliny $\mathrm{z}$ obiektu chronionego chemicznie, ponieważ nie były tak silnie zaatakowane ze strony mszyc, wytwarzały kwiaty, a potem strąki w okresie maksimum lotu strąkowca bobowego. Ochrona z użyciem preparatów niechemicznych (Polyversum WP, Bioczos $\mathrm{BR}$, Biosept $33 \mathrm{SL}$ ) nie wykazała istotnego wpływu na żerowanie strąkowca bobowego.

Analiza energii kiełkowania nasion zebranych z roślin chronionych preparatami niechemicznymi i chemicznymi wykazała zwiększone wartości tej cechy $u$ nasion pochodzących z roślin chronionych zaprawami - zarówno Polyversum WP, jak i Vitavax 200 FS (rys. 3), natomiast nie stwierdzono istotnego wpływu zastosowanej ochrony na zdolność kiełkowania nasion (rys. 4). Była ona dość wysoka i wahała się od około $85 \%$ u nasion z roślin chronionych wyłącznie $\mathrm{z}$ użyciem zapraw (niechemicznej $\mathrm{i}$ chemicznej) do $95 \% \mathrm{u}$ nasion $\mathrm{z}$ roślin chronionych z użyciem insektycydów i fungicydów sztucznie syntetyzowanych.

Cechy morfologiczne siewek na ogół były podobne, niezależnie od użytego sposobu ochrony roślin matecznych (tab. 2). Jedyne różnice, jakie odnotowano, wiązały się z mniejszą długością części nadziemnej siewek z obiektu chronionego wyłącznie zaprawą Polyversum WP oraz mniejszą liczbą korzeni bocznych w porównaniu do kontroli, w przypadku siewek pochodzących od roślin chronionych z użyciem zaprawy Polyversum WP i preparatów Bioczos BR i Biosept 33 SL.

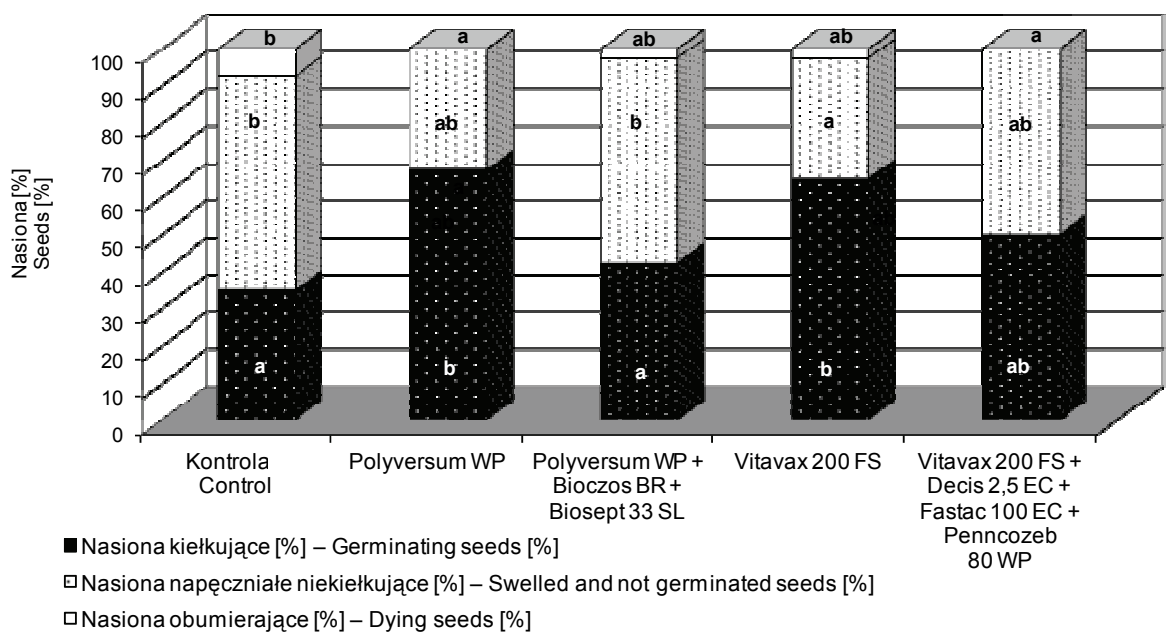

Wartości oznaczone różnymi literami odpowiednio dla danej cechy różnią się istotnie przy a = 0,05

Values for individual features, marked by different letters are statistically different $\alpha=0.05$

Rys. 3. Energia kiełkowania nasion bobu chronionego z użyciem preparatów niechemicznych i chemicznych

Fig. 3. Germination energy of broad bean seeds originated from plants protected with non-chemical and chemical products 


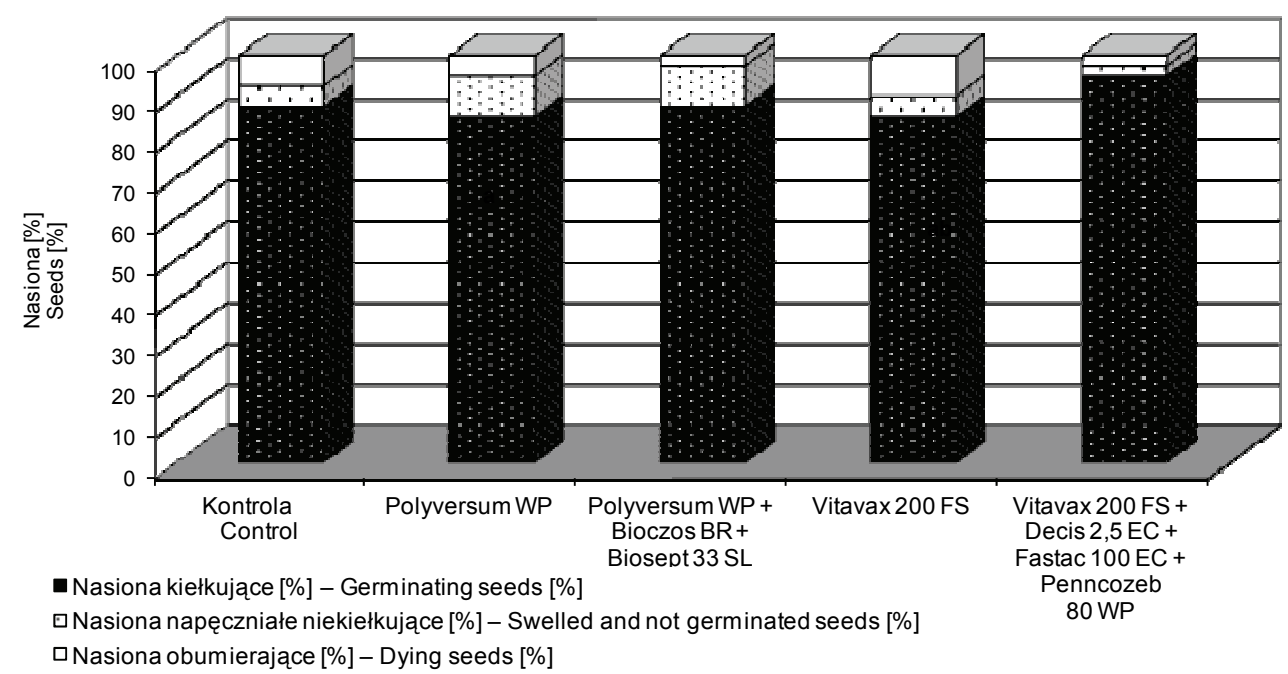

Rys. 4. Zdolność kiełkowania nasion bobu chronionego z użyciem preparatów niechemicznych i chemicznych. Nie stwierdzono istotnego statystycznie zróżnicowania pomiędzy obiektami

Fig. 4. Germination capacity of broad bean seeds originated from plants protected with non-chemical and chemical products. There was not statistical differentiation between treatments

\section{Wnioski / Conclusions}

1. Zastosowana ochrona $\mathrm{z}$ wykorzystaniem preparatów niechemicznych nie wpłynęła istotnie na stopień uszkodzenia nasion przez strąkowca bobowego.

2. Nasiona pochodzące $\mathrm{z}$ roślin chronionych wyłącznie zaprawami Polyversum WP oraz Vitavax 200 FS charakteryzowały się wyższą energią kiełkowania niż z roślin niechronionych.

3. Analizowane sposoby ochrony bobu nie wpływały na zdolność kiełkowania nasion oraz większość cech morfologicznych kiełkujących siewek w porównaniu do kontroli.

4. Skuteczność stosowania w ochronie bobu przed strą- kowcem bobowym preparatów zarówno niechemicznych, jak i chemicznych jest obarczona bardzo silnym wpływem warunków pogodowych panujących w danym roku, co sprawia, że nie zawsze obserwuje się przewagą ochrony chemicznej. W związku z tym (ze względów bezpieczeństwa środowiskowego) należy brać pod uwagę możliwość zastępowania preparatów sztucznie syntetyzowanych, preparatami na bazie substancji naturalnych.

Praca naukowa finansowana ze środków na naukę w latach 2010-2013 jako projekt badawczy NN 310038438.

\section{Literatura / References}

Feng-Lian Y., Guang-Wen L., Yi-Juan X., Yong-Yue L., Ling Z. 2010. Diatomaceous earth enhances the toxicity of garlic, Allium sativum, essential oil against stored-product pests. J. Stored Prod. Res. 46 (2): 118-123.

Gospodarek J., Boligłowa E., Gleń K. 2012a. Porównanie niechemicznego i chemicznego sposobu ochrony bobu przed oprzędzikami (Sitona spp.). [Comparison of the non-chemical and chemical method for broad bean protection against Sitona spp.]. Prog. Plant Prot./Post. Ochr. Roślin 52 (1): 26-30.

Gospodarek J., Gleń K., Boligłowa E. 2012b. Effect of non-chemical preparations application in braod bean protection against harmfulness of broad bean seed beetle (Bruchus rufimanus Boh.) and seed yield. J. Res. Appl. Agric. Engin. 57 (3): 124-128.

Huang Y., Chen S.X., Ho S.H. 2000. Bioactivities of methyl and allyl disulfide and diallyl trisulfide from essential oil of garlic to two species of stored-product pests, Sitophilus zeamais (Coleoptera: Curculionidae) and Tribolium castaneum (Coleoptera: Tenebrionidae). J. Econ. Entomol. 93 (2): 537-543.

Isman M.B. 2000. Plant essential oils for pest and disease management. Crop Prot. 19 (8): 603-608.

Liu C.H., Mishra A.K., Tan R.X., Tang C., Yang H., Shen Y.F. 2006. Repellent and insecticidal activities of essential oils from Artemisia princeps and Cinnamomum camphora and their effect on seed germination of wheat and broad bean. Bior. Tech. 97 (15): 1969-1973.

Tozlu E., Cakir A., Kordali S., Tozlu G., Ozer H., Aytas Akcin T. 2011. Chemical compositions and insecticidal effects of essential oils isolated from Achillea gypsicola, Satureja hortensis, Origanum acutidens and Hypericum scabrum against broad bean weevil (Bruchus dentipes). Sci. Hortic. 130: 9-17.

Wenda-Piesik A., Piesik D. 2009. Skuteczność wyciąu z czosnku w ograniczaniu oprzędzików (Sitona spp.) w uprawie grochu siewnego. [Efficacy of garlic extract in the control of Sitona spp. on pea]. Prog. Plant Prot./Post. Ochr. Roślin 49 (4): $2038-2043$.

Wnuk A., Wojciechowicz-Żytko E. 2010. The influence of intercropping broad bean with phacelia on the occurence of weevils (Sitona spp.) and broad bean beetles (Bruchus rufimanus Boh.). Folia Hort. 22 (2): 33-37. 